\title{
BIOPROSPECÇÃO PARA ATIVIDADE ANTIFÚNGICA DO ÓLEO ESSENCIAL DAS FOLHAS DE Callistemon viminalis
}

\author{
VALENTE, Patrícia Moreira ${ }^{1}$ \\ LOPES, Everaldo Antônio ${ }^{2}$ \\ PEREIRA, Marlon Correa ${ }^{3}$ \\ OLIVEIRA, Cassiano Rodrigues de ${ }^{1}$ \\ VALENTE, Vânia Maria Moreira
}

\begin{abstract}
RESUMO: Alguns fungos são agentes fitopatógenos em determinados estágios das culturas agrícolas, tais como no plantio, durante o desenvolvimento, na colheita, na pós-colheita e, também, no armazenamento, podendo gerar grandes perdas econômicas. A busca por produtos alternativos aos fungicidas sintéticos tem sido objeto de estudos visando obter novos compostos ativos com potencial controle das doenças. Neste sentido, os óleos essenciais mostram-se como alternativa potencial. A espécie arbórea Callistemom viminalis, de origem australiana, é comumente encontrada em território brasileiro, com porte de 3 a 7 metros de altura, folhas pequenas, verdes, perenes e aromáticas, capaz de produzir grande quantidade de flores de coloração vermelha e pequenos frutos, lenhosos e bem aderidos aos ramos. A Callistemom sp. é comumente empregada em silvicultura, paisagismo e na produção de óleo essencial. Neste trabalho, a ação fungicida do óleo essencial de $C$. viminalis foi avaliada sobre os fungos Aspergillus niger, Penicillium expansum e Cladosporium herbarium. O rendimento do óleo foi de $0,9 \mathrm{~mL} / 100 \mathrm{~g}$ de folhas frescas após $1 \mathrm{~h}$ de extração. O óleo apresentou 12 componentes, sendo os principais: eucaliptol ou 1,8-cineol (74,1\%), $\alpha$-terpineol $(11,0 \%)$ e $\alpha$-pineno $(9,2 \%)$, correspondendo a 94,3\% da composição total do óleo. Quando aplicado a uma concentração de $0,2 \%$, o óleo essencial apresentou atividade antifúngica, inibindo o crescimento de $P$. expansum e $C$. herbarium. $\mathrm{O}$ ensaio de cromatografia em camada delgada-bioautografia indicou o eucaliptol e o $\alpha$-terpineol como agentes ativos do óleo de $C$. viminalis, sendo o eucaliptol o agente inibidor para $P$. expansum e o $\alpha$ terpineol como agente inibidor de $C$. herbarium.
\end{abstract}

Palavras-Chave: Cromatografia a gás. Composição química. Fungicida. Fitopatogênicos

SUMMARY: Fungi are phytopatogens of agriculture plantations in specific stages, such as on plantation, during development, on harvesting, on post-haversting and also in storage, causing great economic losses. The search for alternative products to synthetic fungicides is scope of study for many researchers in order to produce new active compounds that may control plant diseases. Thus, essential oils turn up as potential alternative. The Australian tree Callistemom viminalis is commonly found at the Brazilian territory. These trees may reach 3 to 7 meters on height, contain small perennial green leaves with aromatic properties, present reddish flowers and woody fruits, adhered to the branches. The Callistemom sp. is usually applied in silviculture, landscaping and in essential oil extraction. This work presents the evaluation of the antifungal activity of the Callistemom viminalis essential oil on the fungi: Aspergillus niger, Penicillium expansum e Cladosporium herbarium. The extraction yield was $0.9 \mathrm{~mL} / 100 \mathrm{~g}$ of fresh leaves after $1 \mathrm{~h}$. The oil presented 12 components and main compounds were eucalyptol o 1,8-cineol $(74.1 \%), \alpha$ terpineol (11.0\%) and $\alpha$-pinene (9.2\%), corresponding to $94.3 \%$ of the total amount of oil analyzed. When applied at a concentration of $0.2 \%$, the essential oil presented antifungal activity against $P$. expansum and $C$. herbarium. The thin layer chromatography-bioautography revealed that eucalyptol was the inhibitor agent of the $P$. expansum growing and that $\alpha$-terpineol was the inhibitor agent of the $C$. herbarium growing.

Keywords: Gas chromatography. Chemical composition. Fungicide. Phytopatogens

\footnotetext{
${ }^{1}$ Instituto de Ciências Exatas e Tecnológicas, Universidade Federal de Viçosa, Campus Rio Paranaíba. Rodovia MG230, Km 8, Cx. Postal 22, 38810-000, Rio Paranaíba, MG, Brasil.

${ }^{2}$ Instituto de Ciências Agrárias, Universidade Federal de Viçosa, Campus Rio Paranaíba. Rodovia MG-230, Km 8, Cx. Postal 22, 38810-000, Rio Paranaíba, MG, Brasil.

${ }^{3}$ Instituto de Ciências Biológicas e da Saúde, Universidade Federal de Viçosa, Campus Rio Paranaíba. Rodovia MG230, Km 8, Cx. Postal 22, 38810-000, Rio Paranaíba, MG, Brasil.
} 


\section{INTRODUÇÃO}

O controle de agentes fitopatogênicos, de pragas agrícolas e de plantas infestantes é de grande importância para a agricultura. Contudo, os agroquímicos usados para esse fim estão associados a problemas relativos à saúde humana e ao meio ambiente, tais como: toxicidade aos aplicadores; presença de resíduos nos alimentos que afetam o consumidor; e a poluição do solo e da água (SHASANY et al., 2000; OOTANI et al., 2013). Dessa forma, a utilização de compostos de fontes naturais menos impactantes ganha destaque.

Os óleos essenciais de origem vegetal contêm compostos com efeito antibacteriano, antiviral e antifúngico que auxiliam na proteção das plantas contra patógenos em condição natural. Fenilpropanóides e terpenóides são os principais constituintes dos óleos essenciais. Essas classes de substâncias são frequentemente alvo de interesse de pesquisadores que veem nelas uma fonte promissora de princípios ativos diretos ou precursores na síntese de outros compostos de maior importância e valor agregado, como por exemplo, o safrol, eugenol, citral, citronelal, dentre outros (OOTANI et al., 2013). Embora alguns compostos químicos dos óleos extraídos de plantas sejam reconhecidamente capazes de controlar o desenvolvimento de fitopatógenos, poucas espécies vegetais foram estudadas nesses termos (STANGARLIN et al., 1999).

A espécie arbórea Callistemom viminalis, de origem australiana, é comumente encontrada em território brasileiro. Seu porte varia de 3 a 7 metros de altura, com folhas pequenas, verdes, perenes e aromáticas, capaz de produzir grande quantidade de flores de coloração vermelha e pequenos frutos, lenhosos e bem aderidos aos ramos. Sua aplicação está associada à silvicultura, paisagismo, recuperação de áreas degradadas e produção de óleos essenciais (OYEDEJI et al., 2009).

Os óleos essenciais extraídos de $C$. viminalis são compostos em sua maior parte por monoterpenóides oxigenados e eucaliptol (1,8-cineol) (OYEDEJI et al., 2009). A abundância de eucaliptol em $C$. viminalis ocorrentes no Brasil e em outros países é semelhante, porém observam-se diferenças nas quantidades relativas de componentes como $\alpha$-pineno, $\beta$-pineno e $\alpha$-terpineol. Essas diferenças na composição química e no rendimento dos óleos essenciais podem ser atribuídas às variações na constituição genética da planta e aos fatores geográficos e/ou ambientais.

Embora a correlação da atividade biológica com a composição química do óleo essencial seja de difícil associação a um composto específico, a presença de altos teores de eucaliptol pode estar relacionada à potente atividade bactericida encontrada para óleos essenciais destas espécies (SILVA, 2010). Alguns estudos indicam que o óleo essencial bruto apresenta maior atividade bactericida quando comparado aos componentes majoritários testados individualmente, revelando possíveis efeitos de sinergia de atividade (GILL et al., 2002). Isso sugere que os componentes presentes em menor concentração no óleo podem ter ação sinergética potencializando a atividade antimicrobiana do óleo. Além disto, a ação dos óleos essenciais parece depender da cepa de bactéria testada, de forma que o efeito antagônico e/ou sinergético entre os diferentes compostos em misturas complexas como os óleos essenciais devem ser levados em conta (KELEN; TEPE, 2008).

Desta forma, o presente trabalho objetivou, por meio bioprospecção, caracterizar a composição química do óleo essencial de $C$. viminalis, avaliar o efeito do óleo essencial sobre o crescimento dos fungos Aspergillus niger, Penicillium expansum e Cladosporium herbarum e identificar os compostos bioativos. 


\section{MATERIAL E MÉTODO}

\subsection{Extração do óleo essencial}

As folhas de $C$. viminalis foram coletadas em área urbana, de forma aleatória, durante quatro meses subsequentes (agosto a novembro) na cidade de Rio Paranaíba - MG. O óleo essencial foi obtido utilizando aparelho Clevenger, a partir de frações de $300 \mathrm{~g}$ de folhas frescas trituradas com $300 \mathrm{~mL}$ de água destilada. O tempo ótimo de extração foi determinado a partir da relação de volume de óleo extraído em função do tempo de destilação. O óleo foi recolhido e armazenado em um frasco de vidro âmbar e acondicionado em geladeira.

\subsection{Fracionamento do óleo essencial}

O fracionamento do óleo essencial foi realizado por meio de cromatografia em camada delgada (CCD). Diclorometano e hexano foram aplicados como eluentes nas proporções 1:0, 1:1, 1:2, 2:1 e 0:1 v/v com a finalidade de se identificar a proporção com melhor resolução de separação entre os principais componentes do óleo.

Após definição da mistura de eluentes adequada $(1: 1, \mathrm{v} / \mathrm{v})$, aplicou-se o óleo essencial sobre placas $(5 \times 10 \mathrm{~cm})$ de CCD industrializadas, até se formar uma linha ao longo da largura da placa. As diferentes interações dos componentes do óleo entre fase móvel e fase estacionária permitem que ocorra a separação dos mesmos em diferentes frações. A luz ultravioleta foi utilizada para revelar e delimitar as frações. A sílica impregnada com as frações foi recolhida e submetida à extração com diclorometano e analisadas por cromatografia gasosa acoplada à espectrometria de massas, nas mesmas condições do óleo essencial.

\subsection{Análise da composição química do óleo bruto e suas frações}

As amostras de óleo foram analisadas utilizando-se um cromatógrafo a gás Shimadzu QP2010 Plus acoplado a um espectrômetro de massas (CG-EM). As condições cromatográficas das análises foram estabelecidas como descrito por Jardim et al. (2017): coluna capilar de sílica fundida (30 m x 0,25 mm) com fase estacionária RTX5 (0,25 $\mu \mathrm{m}$ de espessura do filme); hélio como gás de arraste vazão de $1,0 \mathrm{~mL}$ $\min ^{-1}$; temperatura do forno inicialmente programada a $60{ }^{\circ} \mathrm{C}$, seguido de aumento de $2{ }^{\circ} \mathrm{C} \min ^{-1}$ até atingir $200{ }^{\circ} \mathrm{C}$, seguido por aumento de $5{ }^{\circ} \mathrm{C} \mathrm{min}^{-1}$ até atingir $280{ }^{\circ} \mathrm{C}$, totalizando $80 \mathrm{~min}$ de análise por amostra. $\mathrm{O}$ volume de $1,0 \mu \mathrm{L}$ da solução contendo $1 \%$ da amostra em diclorometano foi injetado no equipamento por um auto injetor modelo AOC-20i da Shimadzu, em temperatura de $220{ }^{\circ} \mathrm{C}$; a temperatura do detector (ou interface) foi de $240{ }^{\circ} \mathrm{C}$; razão de split de 1:20 e varredura de fragmentos de 45 a 600 $(\mathrm{m} / \mathrm{z})$.

A identificação dos componentes foi feita pela comparação dos espectros de massas com aqueles disponíveis no banco de dados da espectroteca NIST e pelos índices aritméticos (IA). Para o cálculo dos índices, foi injetada no cromatógrafo uma mistura de alcanos lineares (C9 a C17). O IA foi calculado para cada composto e comparado com valores da literatura (ADAMS, 2007), sendo calculado através da equação 1 .

$\mathrm{IA}(\mathrm{x})=100 \mathrm{Pz}+100[\{\mathrm{RT}(\mathrm{x})-\mathrm{RT}(\mathrm{Pz})\} /\{\mathrm{RT}(\mathrm{Pz}+1)-\mathrm{RT}(\mathrm{Pz})\}]$

Onde: 
$\mathrm{x}$, é o composto de interesse;

$\mathrm{Pz}$, é o número de átomos de carbono do hidrocarboneto com tempo de retenção imediatamente anterior ao tempo de retenção de $\mathrm{x}$;

$\mathrm{RT}(\mathrm{x})$, é o tempo de retenção de $\mathrm{x}$;

$\mathrm{RT}(\mathrm{Pz})$, é o tempo de retenção de Z;

$\mathrm{RT}(\mathrm{Pz}+1)$, é o tempo de retenção do hidrocarboneto com tempo de retenção imediatamente posterior ao tempo de retenção de $\mathrm{x}$.

O percentual relativo de cada composto foi calculado através da razão entre a área integral de seus respectivos picos e a área total de todos os constituintes da amostra, dados estes obtidos pelas análises de cromatografia gasosa acoplada à espectrometria de massas.

\subsection{Bioprospecção}

\subsubsection{Avaliação da atividade antifúngica}

Os fungos A. niger, $C$. herbarum e P. expansum foram cedidos pelo Laboratório de Microbiologia da Universidade Federal de Viçosa - Campus Rio Paranaíba.

Preparou-se o meio de cultura com batata dextrose água (BDA) na proporção de 3,9g por $100 \mathrm{~mL}$ de água. $\mathrm{O}$ meio de cultura e os instrumentos de manipulação biológica foram esterilizados por $20 \mathrm{~min}$ a $120{ }^{\circ} \mathrm{C}$ em autoclave. $\mathrm{O}$ meio de cultura foi resfriado até $40{ }^{\circ} \mathrm{C}$ ao qual foram adicionadas alíquotas de óleo essencial para se obter as concentrações de 0,1 e de $0,2 \%(\mathrm{~m} / \mathrm{m})$. Cada mistura contendo uma concentração definida do óleo essencial foi distribuída em três placas de Petri e, em seguida, um inóculo fúngico de aproximadamente $1 \mathrm{~mm}$ de diâmetro foi aplicado no centro da placa. Placas contendo somente BDA foram definidas como controles negativos e placas com cicloexanamida a $0,1 \%(\mathrm{~m} / \mathrm{v})$, como controles positivos. As placas foram vedadas com filme plástico e incubadas a $28{ }^{\circ} \mathrm{C}$ em incubadora de DBO, na ausência de luz, sendo realizada a avaliação do efeito antifúngico do óleo pela medida do diâmetro da colônia expresso em milímetros (DHINGRA e SINCLAIR, 1995). A inibição do crescimento foi determinada por comparação com o tratamento controle através da equação 2 :

$\%$ inibição $=100-[(100 * \mathrm{CV}) / \mathrm{C}]$

Onde:

CV, diâmetro da colônia do tratamento com C. viminalis;

C, diâmetro da colônia do tratamento controle negativo.

\subsubsection{Identificacão do composto bioativo}

A identificação do composto bioativo foi realizada empregando a técnica CCD-bioautografia, empregando cromatografia em camada delgada (CCD), de acordo com Valente et al. (2015).

O sistema CCD-bioautografia foi montado através de placas CCD preparadas com o óleo essencial e desenvolvidas com a mistura diclorometano:hexano (1:1, v/v). Após evaporação do solvente, o meio de cultura BDA contendo esporos dos fungos estudados foi uniformemente distribuído sobre toda a superfície da cromatoplaca, formando um filme com menos de $2 \mathrm{~mm}$ de espessura. O sistema foi então alocado em bandeja úmida coberta com filme plástico e acondicionada em estufa a $28{ }^{\circ} \mathrm{C}$ por sete dias. Após o tempo de incubação, determinou-se a(s) fração(ões) fungitóxica(s) do óleo para cada fungo. Placas CCD sem o óleo foram utilizadas como controle. 


\section{RESULTADO E DISCUSSÃO}

\subsection{Extração do óleo essencial}

Definiu-se o tempo ótimo de extração de óleo essencial das folhas de C. viminalis como 60 minutos (Figura 1), com um volume extraído de 2,8 mL. Considerando-se que, após $120 \mathrm{~min}$, o volume acumulado de óleo extraído foi de 3,0 mL, verificou-se a inviabilidade técnico-econômica da possível extensão do período de extração. O consumo do dobro de energia e de tempo para se obter apenas mais $7,1 \%$ de óleo torna o processo atraente em 60 minutos de duração, apesar de observar diferença na composição química entre $1 \mathrm{~h}$ e $2 \mathrm{~h}$ de extração (Tabela 1). Dessa forma, foi empregado o tempo de 60 minutos para extração de óleo essencial.

Figura 1 - Volume extraído do óleo essencial de folhas de $C$. viminalis em função do tempo.

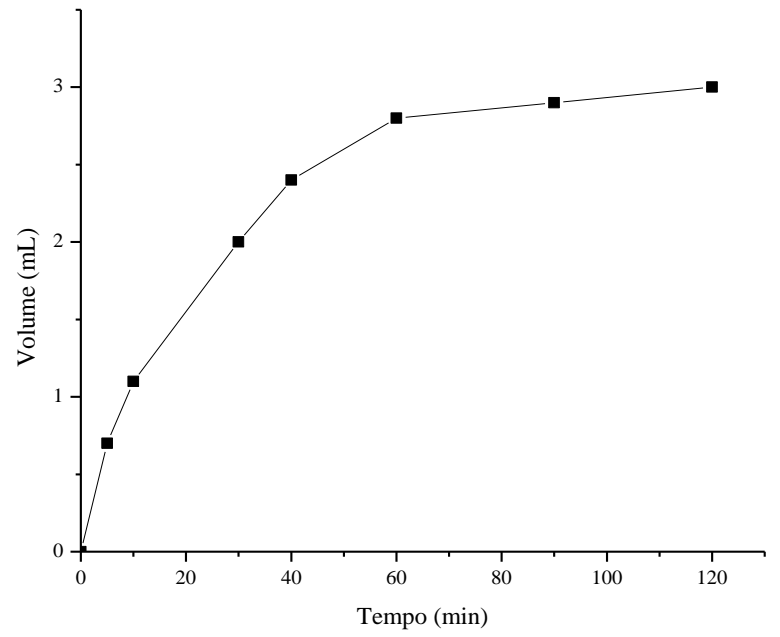

Fonte: Elaborado pelos Autores

O rendimento em 1 h de extração do óleo essencial de $C$. viminalis neste trabalho foi de 0,93 $\mathrm{mL} / 100 \mathrm{~g}$ de folhas frescas, duas vezes maior que as folhas cultivadas no Egito $(0,44 \mathrm{~mL} / 100 \mathrm{~g})$, num tempo de extração de 3h (SALEM et al., 2013) e na Índia, $(0,45 \mathrm{~mL} / 100 \mathrm{~g})$, num tempo de extração de $4 \mathrm{~h}$ (SRIVASTAVA et al., 2003). O valor encontrado é semelhante ao descrito por Oyedeji et al. (2009) que obtiveram $0,9 \mathrm{~mL} / 100 \mathrm{~g}$ na África do Sul após 3h de extração.

\subsection{Fracionamento do óleo}

O eluente que promoveu a melhor separação das frações do óleo essencial foi a mistura de hexano e diclorometano 1:1(v/v). Este foi o eluente empregado nos processos de fracionamento e bioprospecção. O processo de fracionamento do óleo produziu sete frações, identificadas de F01 a F07.

\subsection{Análise da composição química do óleo bruto e suas frações}

Foram identificados 12 compostos majoritários no óleo essencial de C. viminalis (Figura $2 \mathrm{e}$ Tabela 1). O principal composto foi o eucaliptol ou 1,8-cineol com 74,1\% do óleo, seguido de $\alpha-$ 
terpineol com 11,0\% e $\alpha$-pineno com 9,2\%, representando 94,3\% do óleo.

Este resultado está de acordo com outros estudos de composição do óleo essencial de $C$. viminalis da Austrália, Egito, Índia, Paquistão e Ilha da Reunião, constituídos predominantemente por 1,8-cineol (47,9-82,0 \%) (OYEDEJI et al., 2009). A identificação dos três principais compostos deste trabalho é coerente com os aqueles encontrados no óleo de C. viminalis, da África do Sul, em que os autores encontraram doze compostos majoritários (98,3\% do óleo), sendo os principais: 1,8-cineol (83,2 \%), $\alpha$ pineno $(6,4 \%)$ e $\alpha$-terpineol (4,9\%) (OYEDEJI et al., 2009). Os exemplares estudados neste trabalho ainda apresentaram resultado semelhante àqueles cultivados no Egito, que apresentaram 14 compostos, sendo os compostos principais: 1,8-cineol $(64,53 \%)$, seguido por $\alpha$ - pineno $(9,69 \%)$ e $\alpha$ - terpineol $(7,90$ $\%$ ) (SALEM et al., 2013).

Figura 2 - Cromatograma do óleo essencial de folhas C. viminalis.

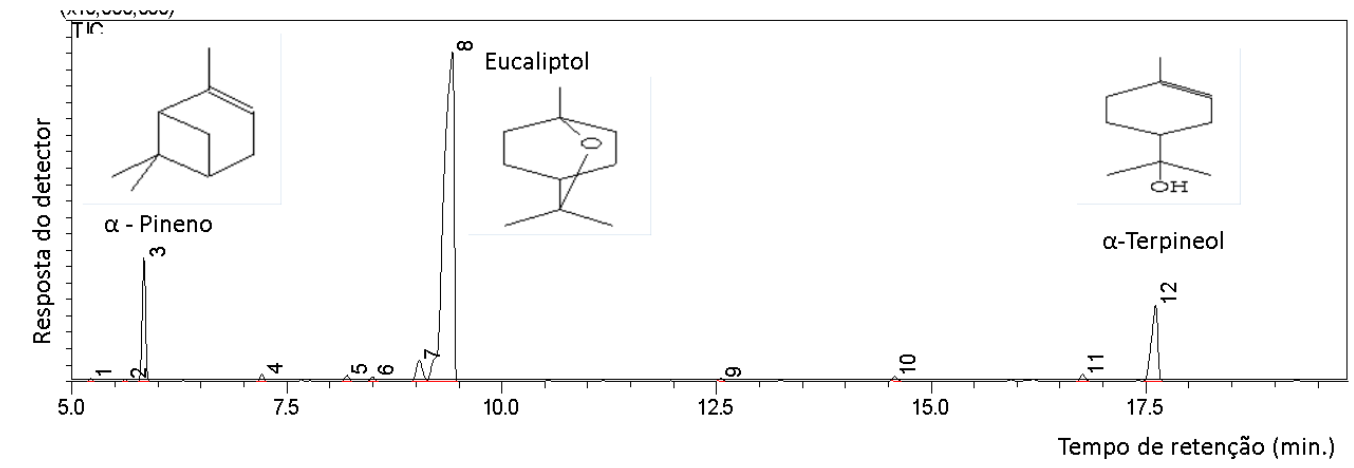

Fonte: Elaborado pelos Autores

O óleo de exemplares indianos de $C$. viminalis possui um número maior de compostos $(42,99,5 \%$ do óleo) do que o número encontrado no presente trabalho, porém com dois compostos principais idênticos: 1,8-cineol (61,7\%), $\alpha$-pineno (24,2\%) e acetato de mentilo (5,3\%) (SRIVASTAVA et al., 2003)

Fatores genéticos definem a composição química dos óleos essenciais, porém, outros fatores podem influenciar e levar a alterações significativas na produção dos metabólitos secundários. Os estímulos do ambiente em que planta se encontra podem redirecionar a rota metabólica, promovendo a biossíntese de diferentes compostos. Dentre esses fatores envolvidos encontram-se as interações plantamicrorganismos, planta-insetos e planta-planta; idade e estádio de desenvolvimento; fatores abióticos como luminosidade, temperatura, pluviosidade, nutrição, época e horário de coleta, bem como técnicas de colheita e pós-colheita (MORAIS, 2009). Outros fatores incluindo composição do solo, presença de agrotóxicos, época de colheita, partes utilizadas da planta, espécie botânica, ventos, entre outros também influenciam na qualidade e na composição química de um óleo essencial (SANTOS et al., 2012).

Os monoterpenóides e sesquiterpenóides produzidos por diversos grupos vegetais são metabólitos frequentemente sujeitos aos fatores abióticos. A baixa intensidade luminosa, por exemplo, geralmente diminui a produção de monoterpenos. Pequenas variações diárias de temperaturas estimulam a produção de terpenóides, enquanto que valores extremos causam sua redução. Os índices de precipitação não seguem um padrão, variando seus efeitos de acordo com a espécie estudada. O aumento dos teores de nitrogênio e fósforo no solo favorece um maior rendimento de óleo essencial extraído (LIMA; KAPLAN; CRUZ, 2003).

Das sete frações obtidas do óleo essencial, foram recolhidos eucaliptol e $\alpha$-terpineol conforme 
pode ser observado na Tabela 1. As frações F01 a F03 contém os dois compostos misturados com predominância do $\alpha$-terpineol, enquanto as frações F04 a F07 contêm apenas eucaliptol.

Diante da disponibilidade de flores no período de coleta das folhas, extraiu-se o óleo essencial das flores de $C$. viminalis conforme protocolo de extração das folhas e sua composição química foi determinada, conforme Tabela 1. O óleo das flores apresentou menor rendimento que o das folhas, com obtenção de $0,6 \mathrm{~mL} / 100 \mathrm{~g}$ de flores frescas, e os principais compostos também foram 1,8-cineol com 56,0 $\%$, seguido de $\alpha$-pineno com $14,6 \%$ e $\alpha$-terpineol com $14,1 \%$, somando $84,7 \%$ do óleo.

\subsection{Bioprospecção}

\subsubsection{Avaliação da atividade antifúngica}

De acordo com os resultados exibidos na Tabela 2, o óleo essencial de $C$. Viminalis induziu o crescimento de A. niger após sete dias de incubação e inibiu o crescimento de $C$. herbarum e $P$. expansum após onze dias. A inibição está diretamente proporcional à concentração de óleo essencial aplicada nos testes biológicos, sendo maior para a espécie $C$. herbarum seguido por $P$. expansum. 
Tabela 1 - Composição química do óleo essencial de $C$. viminallis e suas frações

\section{Concentração (\%)}

\begin{tabular}{|c|c|c|c|c|c|c|c|c|c|c|c|c|c|c|}
\hline Pico & $\begin{array}{c}\text { IS (\%) } \\
\text { NIST }\end{array}$ & IA calc. & IA tab. & Composto & O.E. $1 \mathrm{~h}$ & O.E.2h & $\begin{array}{l}\text { O.E. } \\
\text { flor }\end{array}$ & $\begin{array}{l}\text { F } \\
01\end{array}$ & $\begin{array}{c}F \\
02\end{array}$ & $\begin{array}{c}\mathbf{F} \\
\mathbf{0 3}\end{array}$ & $\begin{array}{l}\text { F } \\
04\end{array}$ & $\begin{array}{c}\text { F } \\
05\end{array}$ & $\begin{array}{c}\text { F } \\
06\end{array}$ & $\begin{array}{c}\text { F } \\
07\end{array}$ \\
\hline 1 & 96 & 912 & 908 & Isobutirato de isobutila & 0,2 & 0,3 & - & - & - & - & - & - & - & - \\
\hline 2 & 93 & 924 & 924 & $\alpha-$ Tujeno & 0,1 & 0,2 & 0,6 & - & - & - & - & - & - & - \\
\hline 3 & 97 & 931 & 932 & $\alpha-$ Pineno & 9,2 & 9,8 & 14,6 & - & - & - & - & - & - & - \\
\hline 5 & 95 & 1004 & 1002 & $\alpha-$ Felandreno & 0,5 & 0,8 & 4,4 & - & - & - & - & - & - & - \\
\hline 6 & 89 & 1011 & 1007 & Iso-butirato de iso-amila & 0,4 & 0,6 & 0,2 & - & - & - & - & - & - & - \\
\hline 7 & 94 & 1022 & 1022 & o-Cimeno & 2,8 & 3,3 & 1,2 & - & - & - & - & - & - & - \\
\hline 10 & 94 & 1135 & 1135 & Trans - Pinocarveol & 0,4 & 1,0 & - & - & - & 3,4 & - & - & - & - \\
\hline 11 & 93 & 1172 & 1174 & Terpinen-4-ol & 0,8 & 1,3 & 1,5 & - & - & - & 3,6 & - & - & - \\
\hline 12 & 93 & 1189 & 1186 & $\alpha-$ Terpineol & 11,0 & 14,5 & 14,1 & 86,4 & 82,9 & 68,8 & - & - & - & - \\
\hline
\end{tabular}


Tabela 2 - Dados do ensaio de atividade antifúngica do óleo essencial de $C$. viminalis.

\begin{tabular}{|c|c|c|c|c|c|c|c|c|c|c|}
\hline \multicolumn{2}{|c|}{$\begin{array}{c}\text { Tempo de acompanhamento do } \\
\text { ensaio }\end{array}$} & \multicolumn{3}{|c|}{4 dias } & \multicolumn{3}{|c|}{7 dias } & \multicolumn{3}{|c|}{11 dias } \\
\hline Fungo & $\begin{array}{c}\text { Concentração } \\
\text { do óleo, \% }\end{array}$ & $\begin{array}{l}\text { Crescimento } \\
\text { médio }(\mathrm{mm})\end{array}$ & $\begin{array}{l}\text { Desvio } \\
\text { Padrão }\end{array}$ & $\begin{array}{c}\text { Inibição } \\
(\%)\end{array}$ & $\begin{array}{l}\text { Crescimento } \\
\text { médio }(\mathrm{mm})\end{array}$ & $\begin{array}{l}\text { Desvio } \\
\text { Padrão }\end{array}$ & $\begin{array}{c}\text { Inibição } \\
(\%)\end{array}$ & $\begin{array}{l}\text { Crescimento } \\
\text { médio }(\mathrm{mm})\end{array}$ & $\begin{array}{l}\text { Desvio } \\
\text { Padrão }\end{array}$ & $\begin{array}{c}\text { Inibição } \\
(\%)\end{array}$ \\
\hline \multirow{4}{*}{$\begin{array}{c}\text { Cladosporium } \\
\text { herbarum }\end{array}$} & $0^{*}$ & 2,9 & 0,1 & 0,0 & 5,1 & 0,1 & 0,0 & 9,0 & 0,0 & 0,0 \\
\hline & 0,1 & 2,1 & 0,1 & 26,4 & 3,6 & 0,6 & 30,1 & 6,7 & 1,2 & 25,6 \\
\hline & 0,2 & 1,5 & 0,1 & 49,4 & 2,9 & 0,2 & 43,1 & 5,1 & 0,5 & 43,7 \\
\hline & 0 & 3,6 & 0,2 & 0,0 & 6,0 & 0,6 & 0,0 & $-* *$ & - & - \\
\hline \multirow[t]{2}{*}{ Aspergillus niger } & 0,1 & 4,3 & 0,1 & $-19,3$ & 6,7 & 0,3 & $-11,1$ & - & - & - \\
\hline & 0,2 & 5,0 & 0,1 & $-36,7$ & 7,7 & 0,2 & $-28,9$ & - & - & - \\
\hline \multirow{3}{*}{$\begin{array}{l}\text { Penicilium } \\
\text { expansum. }\end{array}$} & 0 & 1,7 & 0,1 & 0,0 & 2,8 & 0,1 & 0,0 & 4,8 & 0,1 & 0,0 \\
\hline & 0,1 & 1,6 & 0,1 & 5,8 & 2,6 & 0,2 & 9,4 & 4,0 & 0,8 & 16,8 \\
\hline & 0,2 & 1,5 & 0,1 & 13,5 & 2,5 & 0,2 & 12,9 & 3,0 & 0,7 & 36,4 \\
\hline
\end{tabular}


A cicloexanamida $(0,1 \%)$ foi utilizada como controle positivo, inibindo $100 \%$ do crescimento micelial dos três fungos até o quinto dia. Porém, no décimo primeiro dia, o A. niger apresentou crescimento de 1,3 \pm $1,15 \mathrm{~cm}$, resultando numa inibição final de $83,5 \%$ (Figura $3 \mathrm{E}$ ). O óleo essencial de $C$. viminalis inibiu parcialmente a esporulação de A. niger (Figura 3F), apesar de induzir seu crescimento.

Figura 3 - Halo de crescimento após 11 dias: (A) C. herbarum controle, (B) C. herbarum com cicloexamida $0,1 \%$, (C) $C$. herbarum com óleo de $C$. viminalis $0,1 \%$, (D) A. niger controle, (E) A. niger com cicloexamida $0,1 \%$, (F) A. niger com óleo de $C$. viminalis $0,1 \%$, (G) $P$. expansum controle, (H) $P$. expansum com cicloexamida $0,1 \%$ e (I) $P$. expansum com óleo de $C$. viminalis $0,1 \%$.

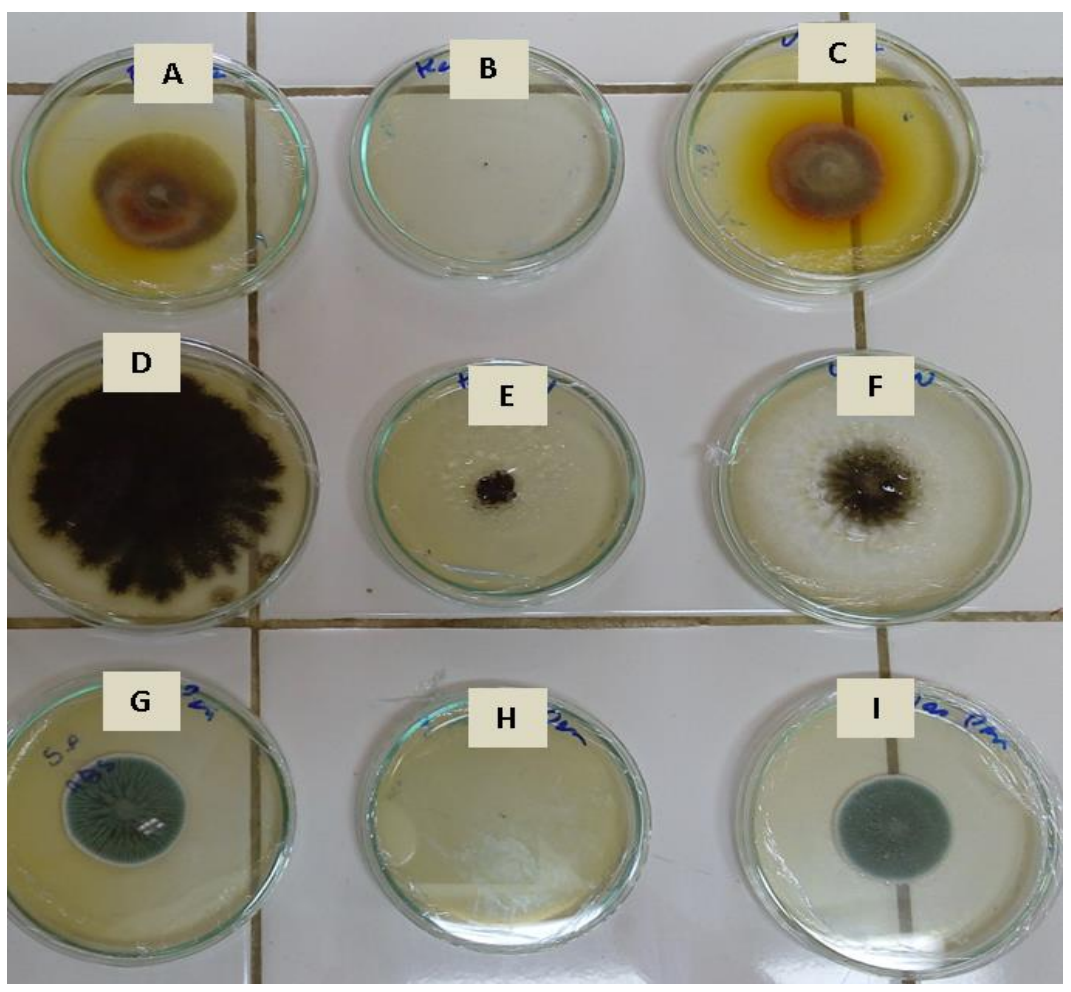

Fonte: Elaborado pelos Autores

Várias classes de compostos orgânicos podem ser encontradas no óleo essencial de $C$. viminalis: fenóis, glicosídeos, flavonóides, alcaloides, saponinas, taninas e esteroides (KAUR; ARORA, 2009, PAREKH; JADEJA; CHANDA, 2005). Flavonóides podem interferir na ação proteica nas paredes celulares bacterianas e alcaloides são aplicados como agentes bactericidas. Em plantas superiores essas classes são controladoras do crescimento de microrganismos indesejáveis. Dentre os componentes principais do óleo essencial de $C$. viminalis, sabe-se que o teor de 1,8-cineol o classifica como medicinal (OYEDEJI et al., 2009), tornando o mesmo um eficiente bactericida (OYEDEJI et al., 2009; SALEM et al., 2013).

Em trabalho recente, Siddique et al. (2017) também estudaram a atividade antifúngica do óleo essencial de C. viminalis em A. niger, Aspergillus flavus, Fusarium oxysporum, Fusarium solani, Alternaria alternata e 
Penicillium digitatum. Os principais componentes do óleo extraído (1,7 mL/ $100 \mathrm{~g}$ após $3 \mathrm{~h}$ de extração) foram a-pineno (31,4 \%) 1,8-cineol (24,9 \%) e p-cimeno (15,9\%). Em ensaios biológicos para A. niger, os pesquisadores observaram ação inibitória do crescimento, com uma concentração mínima de $8 \mu \mathrm{g} / \mathrm{mL}$ de óleo. Este resultado também foi encontrado por Hammer e colaboradores (2003) utilizando o óleo essencial de Melaleuca alternifolia, cujos componentes principais foram terpinen-4-ol, $\alpha$-terpineol, linalol, $\alpha$-pineno, $\beta$ pineno e 1,8-cineol. Por outro lado, há relatos da literatura que descrevem a ausência de inibição em A. niger (AIT-QUAZZOU et al., 2011; CARSON et al., 2011), demonstrando que somente a presença dos componentes ativos supracitados neste presente trabalho não é suficiente para explicar o mecanismo de resistência biológica observado em A. niger.

\subsubsection{Identificação do composto bioativo}

A CCD-bioautografia é uma técnica utilizada para indicar a existência de sinergismo entre os componentes de um material bioativo na inibição de crescimento de microorganismos-alvo. Neste trabalho, os resultados de CCD-bioautografia indicam 1,8-cineol e $\alpha$-terpineol como os agentes antifúngicos do óleo de folhas de $C$. viminalis. O ensaio sugere que 1,8-cineol seja ativo sobre o fungo $P$. expansum, e $\alpha$-terpineol ativo sobre C. herbarum.

Considerando os compostos fungitóxicos, 1,8-cineol e $\alpha$-terpineol, as flores de $C$. viminalis também podem ser empregadas como fonte de óleo essencial para controle de $P$. expansum e $C$. herbarum.

Na literatura, sugere-se que 1,8-cineol e $\alpha$-terpineol sejam componentes ativos contra microrganismos (OYEDEJI et al., 2009; PARK et al.; 2012, SALEM et al.; 2013; SUWANNARACH et al., 2013). Em relação aos fungos investigados neste trabalho, Hammer, Carson e Riley (2003) também relataram a atividade antifúngica do $\alpha$-terpineol, quando aplicado em teores proporcionais aos outros componentes do óleo essencial de Melaleuca alternifólia contra A. niger (concentração inibitória mínima: 0,03\%) e Penicillium sp. (concentração inibitória mínima: 0,016\%).

Outras espécies fúngicas também sofreram inibição de crescimento. Em estudos recentes, os fitopatógenos Vitex agnus-castus on Fusarium oxysporum f. sp. radicis-lycopersici, Rhizoctonia solani, Sclerotinia sclerotiorum e Verticillium dahliae (YILAR; BAYAN; ONARAN, 2016) e o fungo de pós-colheita Pilidiella granati (THOMIDIS; FILOTHEOU, 2016) foram inibidos pela ação de diferentes óleos essenciais. No trabalho de Thomidis e Filotheou (2016), foi observado que em três dos cinco óleos pesquisados, o eucaliptol apresentou-se com composto de maior proporção relativa dentre os componentes identificados. Entretanto, em testes de inibição micelar, este composto não apresentou inibição significativa frente ao fungo Pilidiella granati. Esse fato revela que as interações agente antifúngico-fungo são mais relevantes que o teor do agente presente no óleo. Assim, a CCD-bioautografia mostra-se com técnica eficiente na interpretação de efeitos de sinergia que os componentes de um óleo essencial podem provocar na atividade antifúngica. Para $A$. niger, sugere-se que componentes minoritários presentes no óleo tenham contribuído na ausência de atividade antifúngica.

\section{CONCLUSÃO}

O óleo essencial de $C$. viminalis foi obtido com bom rendimento, composto por 12 substâncias, sendo 
majoritários o 1,8-cineol com 74,1\%, seguido de $\alpha$-terpineol com $11,0 \%$ e $\alpha$-pineno com 9,2 \%, que juntos somam 94,3\% do óleo. Foi observada atividade antifúngica sobre P. expansum e C. herbarum. A CCDbioautografia indicou eucaliptol como principal composto ativo sobre o fungo $P$. expansum e $\alpha$-terpineol sobre $C$. herbarum. Assim, o óleo essencial de $C$. viminalis, apresenta-se como alternativa promissora de combate a estes fungos.

\section{REFERÊNCIAS}

ADAMS, R. P.Identification of essential oil components by gas chromatography/mass spectrometry.4ed. Illinois USA: Allured Publishing Corporation, Carol Stream, 2007, 804 p.

AIT-OUAZZOU, A. et al. The anti- microbial activity of hydrophobic essential oil constituents acting alone or in combined processes of food preservation. Innovation on. Food Science Emerging Technology. v.12, n.13, 320-329, 2011.

ALMEIDA, S. A. et al. Atividade inseticida de extratos vegetais sobre Callosobruchus maculatus (Fabr., 1775) (COLEOPTERA: BRUCHIDAE). Revista brasileira Agrociência, v. 10, n. 1, p. 67-70, 2004.

CARSON, C.F., HAMMER, K.A. Chemistry and Bioactivity of Essential Oils. In Lipids and Essential Oils as Antimicrobial Agents. Chichester, UK: Thormar, C., Ed.; John Wiley \& Sons, 2011.

DHINGRA, O. D., SINCLAIR, J. B. Basic Methods in Plant Pathology. CRC press, Boca Raton, FL. p.448. 1995.

GILL, A.O.et al. Evaluation of antilisterial action of cilantro oil on vacuum packed ham. International Journal of Food Microbiology, v. 73, p. 83-92, 2002.

HAMMER, K. A.; CARSON, C. F.; RILEY, T. V. Antifungal activity of the components of Melaleuca alternifolia ( tea tree ) oil. Journal of Applied Microbiology, v. 95, n. 4, p. 853-860, 2003.

JARDIM, I. N.et al. (E)-cinnamaldehyde from the essential oil of Cinnamomum cassia controls Meloidogyne incognita in soybean plants. Journal of Pest Science, 2017.

KAUR, G. J.; ARORA, D. S. Antibacterial and phytochemical screening of Anethum graveolens Linn., Foeniculum vulgare Mill. And Trachyspermum ammi Linn. Indian Journal of Natural Products and Resources, v. 8, n. 6, p. 611, 2009.

KELEN, M.; TEPE, B. Chemical composition, antioxidant and antimicrobial properties of the essential oils of three Salvia species from Turkish flora. Bioresource Technology, v. 99, p. 4096-4104, 2008.

LIMA, H. R. P.; KAPLAN, M. A. C.; CRUZ, A. V. M. Influência dos fatores abióticos na produção e variabilidade de terpenóides em plantas. Floresta e Ambiente. V. 10, n.2, p.71 - 77, 2003.

MORAIS L.A.S. Influência dos fatores abióticos na composição química dos óleos essenciais. Horticultura Brasileira, v. 27, n. 2, S4050- S4063, 2009.

OOTANI, M. A. et al. Use of Essential Oils in Agriculture. Journal of Biotechnology and Biodiversity, v.4, n.2, p. 162-174, 2013. 
OYEDEJI, O. O. et al. Chemical Composition and Antibacterial Activity of the Essential Oils of Callistemon citrinus and Callistemon viminalis from South Africa. Molecules, v.14, p.1990-1998, 2009.

PAREKH, J.; JADEJA, D.; CHANDA, S. Efficacy of Aqueous and Methanol Extracts of Some Medicinal Plants for Potential Antibacterial Activity. Turkish Journal of Biology, v. 29, p. 203-210, 2005.

PARK, S. N.et al. Antimicrobial effect of linalool and $\alpha$-terpineol against periodontopathic and cariogenic bacteria. Anaerobe, v. 18, n. 3, p. 369-372, 2012.

SALEM, M. Z. M.et al. Evaluation of extracts and essential oil from Callistemon viminalis leaves: Antibacterial and antioxidant activities, total phenolic and flavonoid contents. Pacific Journal of Tropical Medicine, p.785-791, 2013.

SANTOS, V.M.C.S.et al. Alternativas de propagação na produção de óleo essencial de Mentha canadensis L. no Litoral Norte Catarinense. Revista Brasileira de Plantas Medicinais, v. 14, n.1, p. 97-102. 2012.

SIDDIQUE, S.et al. Chemical Composition, Antioxidant and Antimicrobial Activities of Essential oil from Callistemon viminalis (Gaertn.) G. Don Leaves. Journal of Essential Oil Bearing Plants, v. 20, n. 2, p. 524 $534,2017$.

SILVA, C. J. et al. Chemical Composition And Antibacterial Activities From The Essential Oils Of Myrtaceae Species Planted In Brazil. Química Nova, v. 33, p. 104-108, 2010.

SHASANY, A. K.et al. Phenotypic and RAPD diversity among Cymbopogon Winterianus Jowitt accessions in relation to Cymbopogon nardus Rendle. Genetic Resources and Crop Evolution, v. 47, n. 5, p. 553- 559, 2000 .

SRIVASTAVA, S.K.et al. Essential oil composition of Callistemon viminalis leaves from India. Flavour and Fragrance Journal, v.18, n.5, p.361-363, 2003.

STANGARLIN, J. R.et al. Plantas medicinais e o controle alternativo de fitopatógenos. Biotecnologia, Ciência \& Desenvolvimento, v. 2, n. 11, p. 16-21, 1999.

SUWANNARACH, N.et al. Biofumigation with the endophytic fungus Nodulisporium spp. CMU-UPE34 to control postharvest decay of citrus fruit. Crop Protection, v. 45, p. 63-70, 2013.

THOMIDIS, T.; FILOTHEOU, A. Evaluation of fi ve essential oils as bio-fungicides on the control of Pilidiella granati rot in pomegranate. Crop Protection, v. 89, p. 66-71, 2016.

VALENTE, V. M. M.et al. Major Antifungals in Nutmeg Essential Oil against Aspergillus flavus and A. ochraceus. Journal of Food Research, v. 4, n. 1; p.51-57, 2015.

YILAR, M.; BAYAN, Y.; ONARAN, A. Chemical Composition and Antifungal Effects of Vitex agnus-castus L . and Myrtus communis L. Plants, v. 44, n. May, p. 466-471, 2016. 
Nucleus, v.12, n.2, out.2015 